\title{
EDUCAÇÃO PARA A CIDADANIA EM PORTUGAL
}

\author{
EDUCATION FOR CITIZENSHIP IN PORTUGAL
}

Alfredo Gomes Dias ${ }^{1}$

Maria João Hortas ${ }^{2}$

\begin{abstract}
Resumo: A Educação para a Cidadania em Portugal ganha um novo dinamismo e assume uma nova perspectiva com a publicação da Estratégia Nacional da Educação para o Desenvolvimento (2010-2015) e dos documentos de orientação curricular, que reforçam uma abordagem à Educação para a Cidadania Global sustentada no desenvolvimento de competências (2017-2019). É sobre este percurso de uma década que se foca o presente artigo, objetivando compreender os princípios orientadores e finalidades do referencial da Educação para o Desenvolvimento e discutir, numa perspectiva crítica, as potencialidades e limitações dos documentos que operacionalizam a Educação para a Cidadania Global nos currículos em Portugal. A análise, sustentada nos documentos oficiais, reconhece o esforço para colocar na agenda das políticas educativas uma dimensão objetiva de formação cidadã. Contudo, identificam-se algumas contradições que poderão dificultar um desenho curricular comprometido com o desenvolvimento de competências cidadãs numa perspectiva de Cidadania Global.
\end{abstract}

Palavras-chave: Competências; Educação para a Cidadania; Portugal.

Abstract: Education for citizenship in Portugal gains a new dynamic and assumes a new perspective with the publication of National Strategy of Education for Development (2010-2015) and the documents with curricular guidelines, that reinforce the importance of Education for a Global Citizenship based in the competence development (2017-2019). It is about this path of a decade that we focus this article, aiming to understand the guidance principles and the ends of the referential of Education for Development and to discuss, with a critical perspective, the potentialities and limits of the documents put in practice for the Portuguese curriculums of Education for a Global Citizenship. The analyses, sustained in the official documents, recognises the effort to put the dimension of citizenship formation in the education political agenda. However, can be identified some contradictions that might make difficult to create a curricular draw committed to the development of citizenship competences from a perspective of Global Citizenship.

Keyword: Competences; Citizenship Education; Portugal.

Resumen: La educación para la ciudadanía en Portugal adquiere un nuevo dinamismo y adquiere una nueva perspectiva con la publicación de la Estrategia nacional para la educación para el desarrollo (2010-2015) y documentos de orientación curricular, que refuerzan un enfoque de la educación para la ciudadanía Global sostenido en el desarrollo de habilidades (2017-2019). Este artículo se centra en este curso de una década, con el objetivo de comprender los principios rectores y los propósitos del marco de Educación para el Desarrollo y discutir, en una perspectiva crítica, los potenciales y las limitaciones de los documentos que hacen que la Educación para la Ciudadanía Global sea operativa en Brasil. se reanuda en Portugal. El análisis, respaldado por documentos oficiales, reconoce el esfuerzo por colocar una dimensión objetiva de la formación ciudadana en la agenda de las políticas educativas. Sin embargo, se identifican algunas contradicciones que pueden dificultar un diseño curricular comprometido con el desarrollo de habilidades ciudadanas en una perspectiva de Ciudadanía Global.

Palabras clave: Habilidades; Educación para la ciudadanía; Portugal.

1Doutor em Geografia Humana pela Universidade de Lisboa e Doutor em Educação pela Universidade Autónoma de Barcelona, Professor Adjunto no Instituto Politécnico de Lisboa, Escola Superior de Educação, adias@eselx.ipl.pt, ORCID: http://orcid.org/0000-0001-6500-844X

2Doutora em Geografia Humana pela Universidade de Lisboa, Professora Adjunta no Instituto Politécnico de Lisboa, Escola Superior de Educação, mjhortas@eselx.ipl.pt, ORCID: https://orcid.org/0000-0002-3159-8362 


\section{INTRODUÇÃO}

Depois da Revolução de Abril de 1974, a democratização da vida política portuguesa permitiu que a educação para a cidadania ocupasse um espaço cada vez mais relevante no campo do ensino formal.

À entrada no século XXI, intensificaram-se as transformações na relação entre sociedade e escola, decorrentes da generalização do modo de vida urbano, da diversificação dos públicos escolares e das mudanças nos processos de socialização primária das crianças e jovens (CLAUDINO; HORTAS, 2015). Estes são novos desafios que se vivem em simultâneo com a emergência de uma nova ordem econômica e social, com situações de extremismo violento e de desconfiança face aos processos democráticos, que colocam em causa a liberdade e a tolerância (COMISSÃO EUROPEIA, 2018, documento eletrônico).

Neste contexto, têm-se multiplicado as publicações por parte dos organismos europeus e internacionais, na forma de estudos e relatórios, de declarações e de cartas. A título de exemplo, a Comissão Europeia (através da Recomendação 2006/962/EC do Parlamento Europeu e do Conselho, de 18 de dezembro de 2006) apresentou o quadro de Competências Essenciais e, em 2015, produziu a Declaração de Paris; em 2016, o Conselho da Europa publicou o quadro de referência Competences for democratic culture: Living together as equals in culturally diverse societies e, em 2017, os resultados da monitorização da implementação da Carta sobre Educação para a Cidadania Democrática e para os Direitos Humanos. Na mesma linha, a UNESCO, ancorada no Modelo de Educação para a Cidadania Global (2015), tem defendido e promovido uma concepção de educação para a cidadania à escala global. Também a Associação Internacional para a Avaliação do Desempenho Escolar (IEA) publicou os resultados do seu estudo internacional sobre a formação cívica e a cidadania (SCHULZ et al., 2017).

Tomando por referência o relatório Eurydice, a educação para a cidadania define-se como:

uma área disciplinar que tem por objetivo a promoção de uma coexistência harmoniosa e o fomento do desenvolvimento mutuamente benéfico dos indivíduos e das comunidades em que se integram. Nas sociedades ditas democráticas, a educação para a cidadania ajuda os estudantes a tornarem-se cidadãos ativos, informados e responsáveis, dispostos e aptos para assumir as suas responsabilidades individuais e das respetivas comunidades a nível nacional, europeu e internacional (COMISSÃO EUROPEIA 2018, p. 3, documento eletrônico).

De um modo geral, as quatro áreas de competências da educação para a cidadania valorizam: (i) a interação de forma eficaz e construtiva com os outros; (ii) o desenvolvimento do espírito crítico; (iii) a intervenção socialmente responsável; e (iv) a ação democrática (COMISSÃO EUROPEIA, 2018, documento eletrônico). Estas competências desenvolvem-se assumindo duas abordagens: de âmbito disciplinar, com um enfoque autônomo ou integrado, frequentemente ligado às humanidades ou às ciências sociais; de âmbito transversal ao currículo, dentro e fora da sala de aula e ao longo da escolaridade.

Sobre a escola recaem agora as expectativas de uma educação capaz de promover o crescimento e o desenvolvimento global do indivíduo num determinado contexto social e, para tal, esta deve ser capaz de pensar um currículo que integre a tradicional componente disciplinar/científica com uma formação social que assegure às crianças e jovens as competências para saber ser, estar e agir em sociedade. Ou seja, formar cidadãos competentes em termos pessoais, interpessoais e sociais, capazes de refletir criticamente para uma ação democrática no sentido da promoção do bem-estar social.

No presente artigo, procura-se apresentar e discutir as atuais linhas orientadoras da Educação para a Cidadania em Portugal, através dos referenciais que a sustentam e dos documentos que orientam a sua operacionalização. Para esta reflexão, definem-se quatro objetivos gerais: (i) apresentar de forma sucinta os primeiros passos na educação para a cidadania em Portugal; (ii) caraterizar o percurso e os paradigmas que sustentam a sua estratégia nacional de educação para o desenvolvimento; (iii) compreender os princípios orientadores e as finalidades do Referencial da Educação para o Desenvolvimento e o lugar da educação para a cidadania; (iv) discutir, numa perspectiva crítica, as potencialidades e limitações dos documentos orientadores da operacionalização da educação para a cidadania nos currículos do Ensino Básico e Secundário.

De modo a responder aos objetivos traçados e valorizando uma análise crítica dos atuais 
referenciais da educação para o desenvolvimento, recorremos aos seguintes documentos: Estratégia Nacional de Educação para o Desenvolvimento (2010-2015), promovido pelo Instituto Português de Apoio ao Desenvolvimento; Referencial de Educação para o Desenvolvimento - Educação Pré-Escolar, Ensino Básico e Ensino Secundário (CARDOSO, TEOTÓNIO PEREIRA e NEVES, 2016); Perfil dos alunos à saída da escolaridade obrigatória (MARTINS et al., 2018); e, Aprendizagens essenciais. Ensino básico (APRENDIZAGENS ESSENCIAIS, 2018).

Este artigo estrutura-se em quatro partes fundamentais - (1) Educação para a Cidadania em Portugal: primeiros passos; (2) Estratégia Nacional de Educação para o Desenvolvimento (2010-2015): percurso e paradigmas; (3) Referencial da Educação para o Desenvolvimento (2017): princípios orientadores e finalidades, e (4) Considerações Finais.

\section{EDUCAÇÃO PARA A CIDADANIA EM PORTUGAL: primeiros passos}

Em Portugal, a preocupação com a formação cidadã surge ao longo do tempo nas orientações dos responsáveis políticos, plasmadas nas sucessivas reformas educativas. Se remontarmos ao século XVIII, encontramos nas reformas do Marquês de Pombal, aquando da criação das escolas de "primeiras letras" para crianças, a referência ao ensino de Regras de Civismo. Mais tarde, os liberais oitocentistas assumiram, para a educação primária, a necessidade dos mais jovens identificarem-se com o novo regime político e, deste modo, os autores dos manuais de História e Geografia produziram também os compêndios de civismo (CLAUDINO; HORTAS, 2015).

A nova reforma liberal da educação primária definiu a aprendizagem de Breves Noções de História, de Geografia e da Constituição (CLAUDINO, 2000), prevendo assim uma formação disciplinar associada à formação cidadã. Com o advento da I República (1910-1926), o Decreto-Lei de 22 de outubro de 1910, num momento de laicização do ensino, introduziu a disciplina de Educação Cívica, extinguindo o ensino da doutrina cristã, tradição das escolas primárias e normais (PINTASSILGO, 1998; NOGUEIRA, 2015). Contudo, o discurso educativo não defendia uma formação para a participação ativa na comunidade: apelava, tão somente, ao conhecimento dos novos princípios políticos, administrativos e morais (CLAUDINO; HORTAS, 2015). Uma ideia de cidadania concebida, principalmente, como estatuto e associada ao desempenho de um determinado papel social (BÏRZEA, 2000).

Entre 1926 e 1974, Portugal viveu o longo período da ditadura do Estado Novo, um regime político que não contemplava a formação para participação cívica nas orientações que definia para a educação. Reforçou-se novamente a componente religiosa que se manteve até ao final do regime, num sistema educativo marcado também pelo conservadorismo e nacionalismo (NOGUEIRA, 2015). A instauração do novo regime democrático, em 1974, retomou as questões da formação cidadã, ainda que durante os primeiros dez anos de uma forma pouco definida, resultado da instabilidade política e das fragilidades dos próprios governos.

A integração de Portugal na CEE e a progressiva estabilidade social e econômica que o país foi adquirindo, abriram o caminho para a construção de um novo percurso em matéria de educação e de cidadania, enfatizando a dimensão prática do conceito associada a um modelo de cidadania que valoriza a dimensão social e a convivência entre indivíduos em circunstâncias e situações diversas (AUDIGIER, 2000 documento eletrônico). A aprovação em 1986, pelo parlamento português, da Lei de Bases do Sistema Educativo é disso exemplo, assumindo-se como uma referência na perspectiva do desenvolvimento de cidadãos críticos e solidários. Aproximando-se, assim, de uma visão de cidadania associada à intervenção na esfera pública, na comunidade de pertença, colocando os indivíduos como protagonistas na construção social (BARTOLOMÉ, 2005, documento eletrônico).

A reforma curricular de 1986, contextualizada numa fase de rápidas e aceleradas mudanças em Portugal, estabeleceu a criação de uma área transversal de Formação Pessoal e Social. Esta área, à semelhança de outras propostas inovadoras, materializou-se numa organização curricular assente na criação da Área-Escola (integrando a componente de Educação Cívica no $30^{\circ}$ ciclo), nas formações transdisciplinares que incluíam a disciplina de Desenvolvimento Pessoal e Social, nas Atividades de 
Complemento Curricular e nas Atividades de Apoio Pedagógico (ALONSO et al., 2001). Apesar da inovação que esta proposta representou no seu tempo, a sua operacionalização fracassou por motivos de natureza diversa. Contudo, tornaram-se evidentes as preocupações com a Educação Cívica e a Formação Pessoal e Social, quer como áreas autónomas, quer como formação transversal ao currículo.

Passados cerca de dez anos, a publicação do Documento Orientador das Políticas para o Ensino Básico (MINISTÉRIO DA EDUCAÇÃO, 1998), sintetizava os aspetos a considerar na reorganização curricular do ensino básico, sublinhando que a escola precisava de se assumir como um espaço privilegiado de Educação para a Cidadania (EpC). Sustentada, em grande medida, nestas ideias, a Reorganização Curricular, promovida pelo Ministério da Educação em 2001, apresentou-se com um discurso preocupado com as questões da cidadania, prevendo a criação de áreas curriculares não disciplinares como a Área de Projeto e a Formação Cívica. O currículo nacional passou a ser pensado em torno do desenvolvimento de competências (gerais e específicas), integrando o conhecimento, as capacidades e as atitudes e valores, no sentido da construção de um conhecimento para a ação ou dos "saberes em uso" (ABRANTES, 2001).

Além de ocupar um tempo específico no plano curricular de cada um dos ciclos do ensino básico, o diploma consagrou também a EpC como área de caráter transversal e como formação interdisciplinar, no âmbito do ensino básico, entendendo a Formação Cívica como

espaço privilegiado para o desenvolvimento da educação para a cidadania, visando o desenvolvimento da consciência cívica dos alunos como elemento fundamental no processo de formação de cidadãos responsáveis, críticos, activos e intervenientes, com recurso, nomeadamente, ao intercâmbio de experiências vividas pelos alunos e à sua participação, individual e colectiva, na vida da turma, da escola e da comunidade (alínea C), Artigo $5^{\circ}$, Decreto-Lei $n^{\circ} 6 / 2001$ ).

A cidadania é então apresentada como área transversal a todas as disciplinas e áreas do currículo e, ao mesmo tempo, integradora, pois constituía-se como espaço de integração de saberes de diferente natureza (ABRANTES, 2002). Um espaço que objetiva formar cidadãos para a participação pública, que na perspectiva de Benedicto e Morán (2002) significa proporcionar aos indivíduos conhecimentos, competências, valores e sentimentos que garantam uma implicação efetiva na sociedade.

Com as mudanças curriculares introduzidas em 2012, interrompeu-se abruptamente o caminho que há dez anos vinha sendo construído, para assumir a Educação para a Cidadania enquanto área transversal, portanto passível de ser abordada em todas as áreas do currículo. Nesta mudança radical, estabelecemse conteúdos e orientações programáticas, mas retira-se a obrigatoriedade de oferta como disciplina curricular isolada, deixando às escolas o ônus, sob o argumento da autonomia, para decidir sobre os modos de integração e operacionalização, quer como área transversal, quer enquanto disciplina autónoma. Neste sentido, as mudanças curriculares de 2012 retomaram o discurso da transversalidade da EpC, suprimiram as áreas curriculares antes criadas e, em geral, desvalorizaram, de facto, a Educação para a Cidadania.

Apesar das mudanças de discurso, quando comparado com a fase anterior à revolução, a EpC está tradicionalmente desvalorizada nos currículos do ensino básico e secundário, surgindo uma formação cívica mais conotada com os princípios dos sucessivos regimes que com uma efetiva participação crítica na vida comunitária (CLAUDINO; HORTAS, 2015).

\section{ESTRATÉGIA NACIONAL DE EDUCAÇÃO PARA O DESENVOLVIMENTO (2010-2015): percurso e paradigmas}

Em 2008-2009, quando ainda estava em vigor a Reorganização Curricular de 2001 e a Formação Cívica funcionava como uma disciplina autônoma e como área transversal ao currículo, Portugal iniciou um processo de discussão participada com a finalidade de construir uma Estratégia Nacional de Educação para o Desenvolvimento (ENED).

Tendo por referenciais as orientações do Conselho da Europa, da União Europeia e do Comitê de Ajuda ao Desenvolvimento da Organização para a Cooperação e Desenvolvimento Econômico, a ENED mobilizou organismos oficiais - Ministério da Educação e Instituto Português de Apoio ao 
ISSN $1983-1579$

Doi: $10.22478 /$ ufpb.1983-1579.2020v13n1.51562

http://periodicos.ufpb.br/ojs2/index.php

Desenvolvimento - e a Plataforma Portuguesa das Organizações Não-Governamentais para o Desenvolvimento (ONGD). Concebida para o quinquênio 2010-2015, foi posteriormente decidido o seu prolongamento até dezembro de 2016 , momento em que se concretizou a sua avaliação ${ }^{3}$.

A construção deste documento orientador para a Educação para o Desenvolvimento (ED) em Portugal recorreu a uma metodologia participada que garantiu o envolvimento de diferentes atores nacionais, que se organizaram em dois grupos de trabalho, e uma terceira equipe que teve como missão a redação do documento final: Estratégia Nacional de Educação para o Desenvolvimento (2010-2015) (IPAD, 2010). O primeiro grupo de trabalho foi constituído por organismos oficiais e por elementos das Organizações Não-Governamentais para o Desenvolvimento (ONGD) e teve por principal função a identificação e mobilização dos atores mais relevantes neste domínio, recolhendo os seus contributos. $O$ segundo grupo de trabalho integrou responsáveis de diferentes instituições (associações e fundações, entre outras) com experiência de trabalho em diferentes áreas de atuação, nomeadamente, ambiente, diálogo intercultural, igualdade de género, educação. As suas principais tarefas consistiram na definição do quadro conceitual e na apresentação de sugestões e propostas para a Estratégia Nacional.

O trabalho realizado por estes dois grupos processou-se em quatro fases: (i) o exercício sistemático de experiências, que permitiu produzir recomendações a partir das experiências e aprendizagens resultantes das práticas; (ii) a incorporação da experiência resultante da rede europeia Global Education Network Europe (GENE) na definição da ENED; (iii) a consulta pública, permitindo alargar a discussão e integrar novas contribuições; finalmente, (iv) a aprovação e elaboração do Plano de Ação, integrado na ENED.

No âmbito da definição do seu quadro conceitual, a ENED desenhou o percurso realizado em Portugal no domínio da Educação para a Cidadania e, mais recentemente, na Educação para o Desenvolvimento, reconhecendo como fundamental respeitar a reflexão e as experiências acumuladas nas últimas décadas.

No campo das organizações da sociedade civil, as ONGD portuguesas definiram a ED como um processo dinâmico, interativo e participativo, que visa a promoção integral das pessoas. Este olhar holístico passa pela consciencialização e compreensão das causas dos problemas de desenvolvimento e das desigualdades, em diferentes escalas, locais e globais, num contexto de interdependência, assumindo o compromisso para a ação transformadora alicerçada na justiça, na equidade e na solidariedade. Tendo em conta que a realidade das sociedades do século XXI é vincadamente influenciada pelos movimentos migratórios e pela diversidade cultural, a qual se cruza com o agravamento das desigualdades sociais, quer nos espaços nacionais, quer entre as diferentes regiões do globo, importa promover a vivência da interculturalidade sem omitir a necessidade de garantir os direitos e deveres de todas as pessoas e povos a participarem e a contribuírem para um desenvolvimento integral e sustentável. Trata-se, pois, de garantir os conhecimentos necessários à convivência num mundo globalizado, à promoção das relações entre indivíduos e culturas distintas, numa perspectiva de direitos humanos (ROSS, 2001; BANKS, 1997), assegurando uma dimensão afetiva e ética, relacionada com sentimentos de pertença, e o desenvolvimento de capacidades para intervir socialmente (MAIZTEGUI; EIZAGUIRRE, 2008).

Esta perspectiva, aprofunda-se no documento Uma visão estratégica para a cooperação portuguesa (IPAD, 2006), que define a ED como um processo educativo contínuo que favorece as inter-relações sociais, culturais, políticas e econômicas entre o Norte e o Sul, e que promove valores e atitudes de

\footnotetext{
3 A Estratégia Nacional de Educação para o Desenvolvimento (2010-2015) foi aprovada pelo Secretário de Estado dos Negócios Estrangeiros e da Cooperação e pelo Secretário de Estado Adjunto da Educação, através do Despacho n. ${ }^{\circ} 25931 / 2009$, publicado no Diário da República, $2 .^{a}$ série, n. ${ }^{\circ} 230$, de 26 de novembro, pp. 48391-48402. O período de vigência da ENED e do correspondente Plano de Ação foram prorrogados até 31 de dezembro de 2016, através do Despacho n. ${ }^{\circ}$ 9815/2015, do Secretário de Estado dos Negócios Estrangeiros e da Cooperação e do Secretário de Estado do Ensino Básico e Secundário, publicado no Diário da República, 2. ${ }^{a}$ série, n. ${ }^{\circ}$ 168, de 28 de agosto, pp. 24839 24840 .
} 
solidariedade e justiça que devem caracterizar uma cidadania global responsável.

A 'educação para o desenvolvimento' (ED) constitui um processo educativo constante que favorece as interrelações sociais, culturais, políticas e económicas entre o Norte e o Sul, e que promove valores e atitudes de solidariedade e justiça que devem caracterizar uma cidadania global responsável. Consiste, em si mesma, num processo activo de aprendizagem que pretende sensibilizar e mobilizar a sociedade para as prioridades do desenvolvimento humano sustentável (IPAD, 2006, p. 45).

Embora não tendo avançado com uma definição acabada de Educação para o Desenvolvimento, a ENED identificou as suas dimensões: (i) a ED deve ser definida como um processo de aprendizagem (dimensão pedagógica); (ii) os princípios que norteiam o pensamento e a ação em ED são a solidariedade, a equidade, a justiça e a inclusão (dimensão ética); (ii) o objetivo mobilizador da ED é direcionado para a transformação social, assente numa autorreflexividade crítica permanente (dimensão política).

Neste quadro conceptual, a ENED não podia ignorar que se têm vindo a desenvolver abordagens diferenciadas, as quais se traduzem na Educação para os Direitos Humanos, Educação Ambiental, Educação Intercultural, Educação para a Igualdade de Gênero, entre outras. Por isso, sem descurar as suas complementaridades centradas na educação para a transformação social, a ENED considerou importante identificar as especificidades da ED: (i) centralidade das realidades e perceções do Sul ou das periferias num sistema de interdependências Norte-Sul e/ou centro-periferia; (ii) explicitação das causas estruturais dos problemas globais e locais, das desigualdades e das injustiças; (iii) questionamento do desenvolvimento, tanto na sua vertente teórica como prática (IPAD, 2010).

Assumindo que a ENED em Portugal se devia orientar pelos princípios da equidade, justiça social, cooperação, solidariedade, corresponsabilidade, participação e coerência, o seu objetivo geral foi dirigido para a necessidade de "promover a cidadania global através de processos de aprendizagem e de sensibilização da sociedade portuguesa para as questões do desenvolvimento, num contexto de crescente interdependência, tendo como horizonte a acção orientada para a transformação social" (IPAD, 2010, p. 28).

Para a concretização deste objetivo geral, a ENED definiu um conjunto de objetivos específicos aos quais associou um plano de ação:

1 - promover a capacitação das entidades públicas e das organizações da sociedade civil relevantes enquanto atores da ED e criar dinâmicas e mecanismos de diálogo e de cooperação institucional;

2 - promover a consolidação da ED no setor da educação formal em todos os níveis de educação, ensino e formação, contemplando a participação das comunidades educativas;

3 - promover o reforço da ED na educação não-formal, contemplando a participação de grupos diversos da sociedade portuguesa;

4 - promover atividades de sensibilização e de influência política implicando concertação entre atores (IPAD, 2010, p. 28).

\section{REFERENCIAL DA EDUCAÇÃO PARA O DESENVOLVIMENTO (2017): princípios orientadores e finalidades}

Como foi referido anteriormente, o governo português decidiu prorrogar o fim da execução da ENED para 31 de dezembro de 2016 e proceder à sua avaliação, entregando esta tarefa à Faculdade de Psicologia e Ciências da Educação da Universidade do Porto. Metodologicamente, a equipe avaliadora definiu o princípio de garantir o "envolvimento da maior diversidade possível de atores que participaram na implementação da ENED, de forma a dar relevo a uma pluralidade de vozes e sentidos atribuídos à ação" (SÁ COSTA; CARAMELO, 2017, p. 5).

O relatório produzido (SÁ COSTA; CARAMELO, 2017) apresenta o estudo desenvolvido em torno da avaliação da ENED de Portugal, o qual chegou a um conjunto de conclusões, algumas das quais merecem particular destaque. 
Em primeiro lugar, é dada ênfase à existência de uma "Estratégia Nacional de Educação para o Desenvolvimento". Considerando os desafios do mundo atual, a definição de uma estratégia nacional para esta área é identificada como politicamente importante, pelo seu contributo na formação de cidadãos conscientes e participativos, constituindo-se como uma resposta às recomendações de diferentes instâncias internacionais para este domínio da educação.

A existência da ENED enquadrou e legitimou as ações de ED, permitindo a organização e sistematização do setor e permitiu uma série de ganhos do ponto de vista operacional e substantivo reconhecidos por uma diversidade de atores. A constatação, para além dos ganhos obtidos, de aspetos ainda a alcançar, bem como as recomendações internacionais em matéria de ED, consubstanciam a relevância prática e política da ENED (SÁ COSTA; CARAMELO, 2017, p. 6).

Uma segunda conclusão centra-se no impacto positivo da ENED nas práticas de Educação para o Desenvolvimento das entidades que a promovem. No período de vigência da ENED, aumentaram a importância das atividades desenvolvidas pelas entidades promotoras e o número de entidades a desenvolver ações neste campo.

A apropriação da ENED pelas entidades promotoras fez-se segundo lógicas de continuidade, consolidação e alargamento do seu trabalho em ED. O impacto da ENED nos promotores traduz-se, essencialmente, no reconhecimento político da ED pela tutela e pela legitimação das ações de ED que esse reconhecimento confere, o que permitiu incrementar as ações de ED das entidades (SÁ COSTA; CARAMELO, 2017, p. 7).

No que concerne à terceira conclusão a destacar, esta reconhece que a concepção de Educação para o Desenvolvimento, materializada pela ENED, é a de Educação para a Cidadania Global (ECG), o que fica expresso no objetivo geral de "Promover a cidadania global”, bem como nos princípios da Estratégia.

As dimensões e funções da ED destacadas têm discursivamente um âmbito de ação coerente com a cidadania. Os promotores da ENED indicam a "cidadania global" como conceito central da ED e essa centralidade é indicada independentemente da natureza das entidades promotoras e dos modos diferenciados com que atribuem sentido à ED (SÁ COSTA; CARAMELO, 2017, p. 9).

A quarta e última conclusão que importa aqui destacar remete para aquela que é considerada como a área de fragilização da execução da ENED, isto é, a política de financiamento. De facto, o relatório de avaliação afirma que não foram implementadas linhas de financiamento programático que permitissem o alargamento e consolidação da execução da Estratégia Nacional.

A maioria das atividades reportadas são indicadas como sendo financiadas pelos recursos próprios das entidades promotoras tornando a implementação da ENED dependente da sustentabilidade dos promotores e da sua capacidade de garantir financiamento. A inexistência de um financiamento programático e a escassez de recursos humanos, conjugada com a sobreposição de tarefas, condicionou o modo de implementação da ENED, particularmente ao nível do acompanhamento (SÁ COSTA; CARAMELO, 2017, p. 7).

Para além das conclusões, o relatório de avaliação final da ENED avança, também, com um conjunto de recomendações que, no seu conjunto, apontam para a necessidade de alargar e aprofundar em Portugal o trabalho em torno da ED.

É neste sentido que se considera uma prioridade a "atualização da Estratégia, dado o reconhecimento nacional e internacional da sua relevância social, política e educativa", assim como, "alargar e diversificar os promotores da Estratégia". Para tal, seria importante "ampliar a divulgação da, e conhecimento sobre, a Estratégia e as ações desenvolvidas no seu âmbito" (SÁ COSTA; CARAMELO, 2017, pp. 9-10).

Uma última recomendação exige especial atenção: "Ponderar a possibilidade de a Estratégia se assumir explicitamente como de Educação para a Cidadania Global” (SÁ COSTA; CARAMELO, 2017, p. 9). 
Deste modo, a Educação para a Cidadania Global surge no desenvolvimento das concepções e práticas da ED em Portugal e afirma-se como o futuro a construir no domínio da Educação, isto é, como um desafio que se coloca ao sistema educativo português, no seu todo.

Esta linha de orientação começou a afirmar-se em 2012, quando no mês de dezembro é constituído um grupo de trabalho do qual faziam parte técnicos do Instituto da Cooperação e da Língua, da DireçãoGeral da Educação e de duas ONGs (Fundação Gonçalo da Silveira e Centro de Intervenção para o Desenvolvimento Amílcar (abral) com a função de construir um novo documento orientador para o desenvolvimento da ED em contextos de educação formal. Deste modo, surgiu o Referencial de Educação para o Desenvolvimento - Educação Pré-Escolar, Ensino Básico e Ensino Secundário (CARDOSO; TEOTÓNIO PEREIRA; NEVES, 2016).

Na sua introdução, este Referencial define a sua concepção de Educação para o Desenvolvimento, considerando que "visa a consciencialização e a compreensão das causas dos problemas do desenvolvimento e das desigualdades a nível local e mundial, num contexto de interdependência e globalização, com a finalidade de promover o direito e o dever de todas as pessoas e de todos os povos a participarem e contribuírem para um desenvolvimento integral e sustentável" (CARDOSO; TEOTÓNIO PEREIRA; NEVES, 2016, p. 5). No entanto, tal como virá a acontecer no relatório de avaliação final da ENED, os autores deste novo documento dirigido para o sistema educativo formal consideram que a nova visão "favorece sobretudo o enfoque na educação para a cidadania global", tendo por objetivo, de acordo com orientações internacionais (ONU/UNESCO), "capacitar os aprendentes para serem cidadãos globais criativos e responsáveis" (CARDOSO; TEOTÓNIO PEREIRA; NEVES, 2016, p. 6).

Em síntese, o Referencial de Educação para o Desenvolvimento pretende assumir-se como um "documento orientador que visa enquadrar a intervenção pedagógica da Educação para o Desenvolvimento, como dimensão da educação para a cidadania, e promover a sua implementação na educação pré-escolar e nos ensinos básico e secundário" (CARDOSO; TEOTÓNIO PEREIRA; NEVES, 2016, p. 7), de natureza não prescritiva e flexível. Neste sentido, este documento apresenta-se também como um possível instrumento de trabalho para todos os agentes que desenvolvem a sua ação na área da Educação, nomeadamente para quem tem responsabilidades na área da formação inicial e contínua de professores.

No que concerne à sua organização e estrutura interna, o Referencial de Educação para o Desenvolvimento encontra-se organizado por temas globais e por níveis de educação e ciclos de ensino.

No que diz respeito aos temas, foram identificadas seis áreas temáticas "a partir das quais se propõe o tratamento progressivo, desde a educação pré-escolar até aos ensinos básico e secundário" (CARDOSO, TEOTÓNIO PEREIRA e NEVES, 2016, p. 8): (1) Desenvolvimento; (2) Interdependências e Globalização; (3) Pobreza e Desigualdades; (4) Justiça Social; (5) Cidadania Global; (6) Paz.

A identificação destes temas teve em consideração diferentes fatores, entre os quais se contam (i) os referenciais de outros países e de instâncias internacionais; (ii) as aprendizagens da experiência acumulada em Portugal no âmbito da ED/ECG; e, (iii) o desenvolvimento do quadro conceptual que se tem verificado na produção científica em torno da ED/ECG. Uma vez definidos os temas globais, o Referencial de Educação para o Desenvolvimento sintetiza os conhecimentos, capacidades, valores, atitudes e comportamentos a alcançar pelas crianças e jovens em cada um desses temas.

Assim, o Referencial de Educação para o Desenvolvimento encontra-se organizado por níveis de educação e por ciclos de ensino: Educação Pré-Escolar (3-6 anos); $1^{\circ}$ Ciclo do Ensino Básico (6-10 anos); $2^{\circ}$ Ciclo do Ensino Básico (10-12 anos); $3^{\circ}$ Ciclo do Ensino Básico (12-15 anos; Ensino Secundário (15-17 anos). Para cada um destes níveis de educação e ciclos de ensino, são definidos subtemas e objetivos gerais e específicos no âmbito de cada um dos temas.

Ensaiando uma síntese dos temas que se pretendem abordar ao longo da escolaridade obrigatória em Portugal, previstos no Referencial de Educação para o Desenvolvimento, a leitura da Tabela 1 oferecenos uma visão de conjunto das finalidades que este documento propõe que sejam alcançadas pelas crianças e jovens portugueses entre os 3 e os 17 anos de idade. 
Tabela 1 - Temas e Subtemas previstos no Referencial de Educação para o Desenvolvimento

\begin{tabular}{|c|c|}
\hline Temas Globais & Subtemas \\
\hline Desenvolvimento & $\begin{array}{l}\text { Perspectivas e conceitos essenciais associados ao desenvolvimento } \\
\text { Cooperação internacional } \\
\text { Diversidade cultural e visões do mundo } \\
\text { Visões de futuro, alternativas e transformação social }\end{array}$ \\
\hline $\begin{array}{l}\text { Interdependências } \\
\text { Globalização }\end{array}$ & $\begin{array}{l}\text { Interdependências e relação dialética entre o global e o local } \\
\text { Globalização e crescente complexidade das sociedades humanas } \\
\text { Transnacionalização e governação à escala global }\end{array}$ \\
\hline Pobreza e Desigualdades & $\begin{array}{l}\text { Enriquecimento e empobrecimento } \\
\text { Desigualdades, pobreza e exclusão social } \\
\text { Luta contra as desigualdades, a pobreza e a exclusão social }\end{array}$ \\
\hline Justiça Social & $\begin{array}{l}\text { Direitos, deveres e responsabilidades } \\
\text { Bem comum e coesão social e territorial } \\
\text { Construção da justiça social }\end{array}$ \\
\hline Cidadania Global & $\begin{array}{l}\text { A comunidade planetária } \\
\text { Construção de uma sociedade mundial justa e sustentável } \\
\text { Participação e corresponsabilidade }\end{array}$ \\
\hline Paz & $\begin{array}{l}\text { Construção da paz } \\
\text { Situações de insegurança, violência, guerra e ausência de paz } \\
\text { Paz, direitos humanos, democracia e desenvolvimento }\end{array}$ \\
\hline
\end{tabular}

Fonte: Cf. Cardoso, Teotónio Pereira e Neves, 2016.

Com a construção deste Referencial de Educação para o Desenvolvimento abriu-se o caminho para que o sistema educativo introduzisse mudanças nas suas orientações curriculares tendo em vista garantir que o sistema de ensino formal desse resposta às exigências que se erguiam em torno da formação de uma cidadania global durante a escolaridade básica em Portugal.

\section{DAS COMPETÊNCIAS PARA O SÉCULO XXI À “CIDADANIA E DESENVOLVIMENTO” (2018): POTENCIALIDADES E LIMITAÇÕES}

Ao longo do ano de 2018, o Ministério da Educação português divulgou dois novos documentos com orientações para a gestão dos currículos do ensino básico e secundário. O Perfil dos Alunos (MARTINS et al., 2018) e as Aprendizagens Essenciais (DIREÇÃO GERAL DE EDUCAÇÃO, 2018, documento eletrônico) permitem conhecer as atuais apostas da tutela no que respeita à Educação para a Cidadania quer ao nível da definição das competências gerais a desenvolver pelos alunos, quer ao nível das aprendizagens essenciais esperadas em cada uma das áreas disciplinares/disciplinas, por anos de escolaridade.

\subsection{PERFIL DOS ALUNOS: que competências?}

Respeitando a estrutura do texto Perfil dos Alunos, importa analisar o modo como este documento dá expressão à Educação para a Cidadania nas orientações curriculares para o ensino básico e secundário, centrando a nossa atenção nos princípios que define, no perfil que traça para os alunos e nas áreas de competências a desenvolver.

São oito os princípios apresentados que justificam "cada uma das ações relacionadas com a execução e a gestão do currículo na escola, em todas as áreas disciplinares” (MARTINS et al., 2018, p. 9): 
A- base humanista; B- saber; C- aprendizagem; D- inclusão; E-coerência e flexibilidade; F- adaptabilidade e ousadia; G- sustentabilidade; $\mathrm{H}$ - estabilidade.

Cingindo a nossa análise crítica à dimensão da Educação para a Cidadania, são três os princípios que, de algum modo, apontam para finalidades subjacentes ao contributo do ensino formal para a formação cidadã das crianças e dos jovens. Assim, (i) à escola é atribuída a função de habilitar "os jovens com saberes e valores para a construção de uma sociedade mais justa, centrada na pessoa, na dignidade humana e na ação sobre o mundo enquanto bem comum a preservar" - princípio A; (ii) a escolaridade obrigatória é concebida numa lógica "equidade e democracia", devendo ter em conta as diversidades que hoje habitam a escola (socioeconômicas, culturais, cognitivas e motivacionais) e reconhecendo aos alunos o "direito ao acesso e à participação de modo pleno e efetivo em todos os contextos educativos" - princípio D; (iii) à escola é ainda dada a tarefa de formar nos alunos uma "consciência de sustentabilidade", a qual "consiste no estabelecimento, através da inovação política, ética e científica, de relações de sinergia e simbiose duradouras e seguras entre os sistemas social, económico e tecnológico e o Sistema Terra, de cujo frágil e complexo equilíbrio depende a continuidade histórica da civilização humana" - princípio G (MARTINS et al., 2018, pp. 13-14).

Dos três princípios enunciados anteriormente, sobressaem as intencionalidades atribuídas ao ensino formal, no capítulo da Educação para a Cidadania, reconhecendo o seu contributo para a formação de cidadãos que se mobilizem (i) na construção de uma sociedade mais justa, humanista (centrada nas pessoas) e democrática (integradora das diversidades e promotora da participação); e (ii) na preservação de um mundo entendido como um bem comum, através de políticas e práticas ditadas pela sustentabilidade.

Todavia, não podemos deixar de explicitar duas limitações que decorrem da narrativa construída em torno destes princípios. Por um lado, "a construção de uma sociedade mais justa" não pode ser apenas apontada "na ação sobre o mundo enquanto bem comum a preservar", esquecendo aquela que é a ação sobre as desigualdades econômicas e sociais que se agravam à escala regional, nacional e global e que estão na origem de outras desigualdades, diversidades e insustentabilidades. Por outro lado, a "consciência de sustentabilidade" dificilmente atingirá os seus objetivos se não se substituir a lógica da "inovação" pela lógica da transformação dirigida para os efeitos do sistema político, econômico e social dominante que estão na origem da dificuldade em garantir "a continuidade histórica da civilização humana".

Embora estas duas limitações sejam uma constante em todo o documento em análise, também não podemos deixar de sublinhar o passo que é dado no sentido de conceber um sistema educativo em torno do paradigma da construção de uma cidadania democrática e preocupada com a sustentabilidade do planeta. Esta abordagem genérica é reafirmada na "visão de aluno", momento em que o documento define o perfil de saída dos alunos enquanto cidadãos, enunciando um conjunto de competências a desenvolver ao longo da escolaridade obrigatória em Portugal, das quais destacamos (i) "analisar e questionar criticamente a realidade"; (ii) "pensar crítica e autonomamente"; (iii) conhecer e respeitar "os princípios fundamentais da sociedade democrática e os direitos, garantias e liberdades em que esta assenta"; e (iv) valorizar "o respeito pela dignidade humana, pelo exercício da cidadania plena, pela solidariedade para com os outros, pela diversidade cultural e pelo debate democrático" (MARTINS et al., 2018, p. 15).

Reconhecemos que um passo mais longo é dado com a definição deste perfil do aluno, pensandoo enquanto cidadão crítico e democrático, não deixando de se notar a ausência de um traço que torne explícito que a cidadania é, essencialmente, uma praxis, pelo que a Educação para a Cidadania deve também potenciar uma ação transformadora da realidade em que se vive, local e globalmente.

Esta vertente, dirigida não só para o respeito e defesa de princípios e valores abstratos, mas também para a transformação da realidade, é anunciada nos valores que se identificam no Perfil dos Alunos, nomeadamente:

- Cidadania e participação - Demonstrar respeito pela diversidade humana e cultural e agir de acordo com os princípios dos direitos humanos; negociar a solução de 
conflitos em prol da solidariedade e da sustentabilidade ecológica; ser interventivo, tomando a iniciativa e sendo empreendedor.

- Liberdade - Manifestar a autonomia pessoal centrada nos direitos humanos, na democracia, na cidadania, na equidade, no respeito mútuo, na livre escolha e no bem comum (MARTINS et al., 2018, p. 17).

No entanto, mais uma vez, o enunciar de valores e princípios que orientam uma sociedade democrática em torno dos direitos humanos, da negociação de conflitos e do bem comum reduz o ato de agir ao "ser interventivo, tomando a iniciativa e sendo empreendedor", anunciando a continuidade num paradigma de reprodução do sistema político, econômico e social dominante.

Este Perfil dos Alunos concretiza-se na proposta de desenvolvimento de um conjunto de áreas de competências, entendidas nas suas três dimensões: conhecimentos, capacidades e atitudes: (1) linguagem e textos; (2) informação e comunicação; (3) raciocínio e resolução de problemas; (4) pensamento crítico e pensamento criativo; (5) relacionamento interpessoal; (6) desenvolvimento pessoal e autonomia; (7) bem-estar, saúde e ambiente; (8) sensibilidade estética e artística; (9) saber científico, técnico e tecnológico; (10) consciência e domínio do corpo.

Destas 10 áreas de competências podemos reconhecer que cinco estão diretamente relacionadas com aquilo que podemos considerar como o núcleo de uma Educação para a Cidadania, concebida numa lógica de transformação, as quais se desdobram em 12 competências que relacionamos diretamente com a vertente da formação cidadã na construção do Perfil dos Alunos (Tabela 2).

Tabela 2 - Competências relacionadas com a Educação para a Cidadania no 'Perfil dos Alunos'

\begin{tabular}{|l|l|}
\hline Áreas de competências & Competências \\
\hline $\begin{array}{l}\text { pensamento crítico e } \\
\text { pensamento criativo }\end{array}$ & $\begin{array}{l}\text { Pensar de modo abrangente e em profundidade, de forma lógica, } \\
\text { observando, analisando informação, experiências ou ideias, } \\
\text { argumentando com recurso a critérios implícitos ou explícitos, com vista } \\
\text { à tomada de posição fundamentada. } \\
\text { Convocar diferentes conhecimentos, de matriz científica e humanística, } \\
\text { utilizando diferentes metodologias e ferramentas para pensarem } \\
\text { criticamente. } \\
\text { Prever e avaliar o impacto das suas decisões. } \\
\text { Desenvolver novas ideias e soluções, de forma imaginativa e inovadora, } \\
\text { como resultado da interação com outros ou da reflexão pessoal, } \\
\text { aplicando-as a diferentes contextos e áreas de aprendizagem. }\end{array}$ \\
\hline $\begin{array}{l}\text { relacionamento } \\
\text { interpessoal }\end{array}$ & $\begin{array}{l}\text { Adequar comportamentos em contextos de cooperação, partilha, } \\
\text { colaboração e competição. } \\
\text { Trabalhar em equipa e usar diferentes meios para comunicar } \\
\text { presencialmente e em rede. } \\
\text { Interagir com tolerância, empatia e responsabilidade e argumentar, } \\
\text { negociar e aceitar diferentes pontos de vista, desenvolvendo novas } \\
\text { formas de estar, olhar e participar na sociedade. }\end{array}$ \\
\hline $\begin{array}{l}\text { desenvolvimento } \\
\text { pessoal e autonomia }\end{array}$ & $\begin{array}{l}\text { Estabelecer objetivos, traçar planos e concretizar projetos, com sentido } \\
\text { de responsabilidade e autonomia. }\end{array}$ \\
\hline $\begin{array}{l}\text { bem-estar, saúde e } \\
\text { ambiente }\end{array}$ & $\begin{array}{l}\text { Adotar comportamentos que promovem a saúde e o bem-estar, } \\
\text { designadamente nos hábitos quotidianos, na alimentação, nos } \\
\text { consumos, na prática de exercício físico, na sexualidade e nas suas } \\
\text { relações com o ambiente e a sociedade. }\end{array}$ \\
\hline
\end{tabular}




\begin{tabular}{|l|l|}
\hline & $\begin{array}{l}\text { Compreender os equilíbrios e as fragilidades do mundo natural na } \\
\text { adoção de comportamentos que respondam aos grandes desafios } \\
\text { globais do ambiente. }\end{array}$ \\
& $\begin{array}{l}\text { Manifestar consciência e responsabilidade ambiental e social, } \\
\text { trabalhando colaborativamente para o bem comum, com vista à } \\
\text { construção de um futuro sustentável. }\end{array}$ \\
\hline $\begin{array}{l}\text { saber científico, técnico } \\
\text { e tecnológico }\end{array}$ & $\begin{array}{l}\text { Compreender processos e fenómenos científicos que permitam a } \\
\text { tomada de decisão e a participação em fóruns de cidadania. }\end{array}$ \\
\hline
\end{tabular}

Fonte: Cf. MARTINS et al., 2018, p. 23.

De acordo com Pagès e Canals (2011), a competência cidadã constrói-se em torno de quatro dimensões: (i) construir a identidade e desenvolver o pensamento social, adotando uma atitude crítica face aos problemas sociais e às injustiças, presentes e passadas; (ii) situar-se no mundo e agir no sentido da sua sustentabilidade, desenvolvendo a capacidade de ler o território e de interagir com ele através do uso racional dos seus recursos; (iii) construir a consciência histórica, mobilizando uma perspectiva temporal para ler e interpretar os problemas sociais relevantes do mundo de hoje, cruzando o passado, o presente e o futuro; (iv) desenvolver uma consciência cidadã comprometendo-se na defesa dos direitos humanos, tendo por referência as liberdades, a justiça social e a paz.

Naquela proposta do Ministério da Educação português, o pensamento crítico e criativo surge como uma área de competência que merece ser autonomamente considerada, não obstante ser importante considerar que esta está subjacente aos diferentes domínios de desenvolvimento da formação cidadã. Nas restantes quatro áreas, as competências que as concretizam apontam, umas de forma direta, outras indiretamente, para os quatro domínios de competências da EpC apresentadas por Pagès e Canals.

Contudo, o enunciado proposto no Perfil dos Alunos está ainda longe de assumir com clareza as finalidades nucleares da Educação para a Cidadania que, também de acordo com aqueles dois autores, se devem direcionar para o posicionamento do sujeito/cidadão em função (1) dos problemas e injustiças do presente/passado; (2) da análise de situações do quotidiano que põem em causa a sustentabilidade dos territórios; (3) da construção de um futuro alicerçado na análise do passado a partir da problematização do presente; e, (4) de uma visão crítica sobre os direitos humanos centrados nos problemas do quotidiano que afetam os povos, pondo em causa a sua liberdade, a paz e a convivência democrática.

\subsection{CIDADANIA E DESENVOLVIMENTO... QUE CIDADANIA?... QUE DESENVOLVIMENTO?}

Em primeiro lugar, não podemos deixar de reconhecer que as competências a desenvolver no sentido da formação de um cidadão crítico e interventivo nas suas comunidades, quer próxima, quer mais distante, é uma responsabilidade que pertence à escola no seu conjunto e que não diz respeito apenas a esta ou aquela disciplina. Por isso, não podemos deixar também de sublinhar que a criação de uma disciplina autónoma, com a designação de Cidadania e Desenvolvimento (CeD), é um risco que deve ser ponderado e prevenido.

A CeD é considerada uma área transversal no $1^{\circ}$ Ciclo do Ensino Básico (6-10 anos) e funciona como disciplina autónoma desde o $2^{\circ} \mathrm{CEB}$ até ao secundário (10-18 anos), garantindo-se, assim, a sua presença em todos os anos de escolaridade obrigatória.

No enquadramento em que se apresenta esta disciplina para o ensino básico (6-15 anos) anunciase a intenção de garantir a coerência entre os documentos orientadores que foram sendo construídos e sobre os quais tem incidindo a nossa análise: o Referencial de Educação para o Desenvolvimento, o Perfil dos Alunos e as Aprendizagens Essenciais definidas para cada disciplina em cada um dos anos de escolaridade, incluindo o ensino secundário. Neste nível de ensino, de acordo com o Perfil, a escola fica com a responsabilidade de definir a forma como operacionaliza a oferta da CeD: oferta como disciplina autônoma; prática de coadjuvação, no âmbito de uma disciplina; funcionamento em justaposição com outra disciplina; ou abordagem, no âmbito das diferentes disciplinas da matriz, dos temas e projetos, sob coordenação de um dos professores da turma ou grupo de alunos. 
Com esta disciplina é suposto que, ao longo da escolaridade, os jovens desenvolvam as competências necessárias para serem "adultos e adultas com uma conduta cívica que privilegie a igualdade nas relações interpessoais, a integração da diferença, o respeito pelos Direitos Humanos e a valorização de valores e conceitos de cidadania nacional" e que assumam "atitudes e comportamentos, de diálogo e respeito pelos outros, alicerçados em modos de estar em sociedade que tenham como referência os direitos humanos, nomeadamente os valores da igualdade, da democracia e da justiça social" (APRENDIZAGENS ESSENCIAIS, p. 6).

Se retomarmos a Tabela 1, constatamos que os temas definidos para a disciplina de Cidadania e Desenvolvimento se afastam do Referencial para a Educação para o Desenvolvimento e do que de mais inovador apresenta, para se aproximarem de temas e conteúdos que facilmente associamos a algumas das disciplinas do currículo do ensino básico e secundário.

Por outro lado, tal como tivemos ocasião de referir brevemente, uma abordagem à Educação para a Cidadania através da lecionação de uma disciplina autônoma comporta riscos e, do nosso ponto de vista, dois podem ser enunciados. O primeiro é o da descontextualização dos temas abordados como se fossem algo desligado do quotidiano, dos saberes e das experiências que vamos conhecendo ao longo da vida. Outro, talvez o mais relevante, é o da desresponsabilização dos professores das outras disciplinas e da Escola em geral perante o desafio de construir um espaço de aprendizagem democrática no seu todo e não durante 45 ou 90 minutos, numa aula semanal. Trata-se menos de ensinar e aprender democracia e mais de ensinar e aprender vivendo a democracia. Uma aula de Cidadania e Desenvolvimento não resiste à pressão de uma escola antidemocrática e a práticas de ensino centradas exclusivamente na exposição do "mestre", afastadas da discussão de ideias e do debate, e evitando experiências de caráter investigativo.

A velha ideia de que "para educar uma criança é preciso toda a aldeia" facilmente se estende à escola de hoje: a formação cidadã dos jovens que frequentam as escolas exige o envolvimento de todos aqueles que nela desempenham diferentes funções, mas que devem ter como preocupação contribuir para a construção de espaços de ensino e aprendizagem que promovam a cooperação e a autonomia, que validem o conhecimento científico através da experiência e que promovam atitudes/valores democráticos. Caminhos para uma formação cidadã que se desenvolve em torno de competências que ajudem a ler o mundo numa perspectiva global, nas suas inter-relações (econômicas, políticas, sociais), a interpretá-lo e interrogá-lo de forma crítica para nele intervir no sentido da mudança. Como escreve Pagès (2001, p. 273), "la ciudadanía se alcanza cuando los conocimientos sociales se consideran un medio para la promoción y el desarrollo del pensamiento crítico y reflexivo, es decir son una herramienta para la participación y la transformación social".

\section{CONSIDERAÇÕES FINAIS}

Ao longo deste breve estudo, fica claro o modo como os contextos econômicos e sociais e, principalmente, as conjunturas políticas influenciaram os diferentes paradigmas da educação para a cidadania nas várias fases de evolução do sistema educativo português: das regras do civismo à educação cívica, do desenvolvimento pessoal e social à educação para a cidadania, da educação para o desenvolvimento à educação para a cidadania global.

Desde 2008, com o início da construção da Estratégia Nacional da Educação para o Desenvolvimento, esta área de competências ganhou uma nova relevância no sistema de educação formal e nas áreas de intervenção da educação não-formal. Neste capítulo, importa reconhecer o papel desempenhado pela União Europeia e pelas organizações não-governamentais no sentido de colocar na agenda das políticas educativas em Portugal a necessidade de promover, de forma mais consistente, o desenvolvimento de competências cidadãs e de oferecer uma concepção mais ampla que, hoje, se assume numa perspectiva de cidadania global.

Embora reconhecendo as limitações que atrás identificamos, principalmente o não assumir de forma mais corajosa as propostas inovadoras avançadas no Referencial da Educação para o 
Desenvolvimento, não se pode deixar de reconhecer, também, o esforço para incluir nas orientações curriculares uma vertente objetiva de formação cidadã das crianças e dos jovens em Portugal.

Fica, todavia, uma questão relevante que não pode deixar de ser equacionada e que poderá ser o ponto de partida para novos estudos. Como é que os professores interpretam estas orientações? Como se caracterizam as suas práticas? Qual a distância que existe entre as suas concepções e as práticas que desenvolvem? Quais as metodologias que mobilizam? De que modo a formação inicial de professores integra, nos seus planos de estudo, a vertente da educação para a cidadania?

\section{REFERÊNCIAS}

ABRANTES, Paulo. Reorganização curricular do ensino básico: Princípios, medidas e implicações: Decreto-Lei no 6/2001 de 18 de Janeiro. Lisboa: Ministério da Educação, Departamento de Educação Básica, 2001.

ABRANTES, Paulo. Introdução: Finalidades e natureza das novas áreas curriculares. In: Ministério da Educação (Ed.), Reorganização curricular do ensino básico: Novas áreas curriculares. Lisboa: Ministério da Educação, Departamento do Ensino Básico, 2002, p. 7-18.

AUDIGIER, François. Basic Concepts and core competences for education for democratic citizenship. Council of Europe. (DGIV/EDU/CIT (200) 23, 2000. Disponível em: https://www.storiairreer.it/sites/default/files/norme/2000\%2006\%2026\%20Audigier_0.pdf.

Acesso em 20 fev. 2020.

BARTOLOMÉ, Margarita. Construyendo la ciudadanía europea, modelos, programas e iniciativas. $1^{\circ}$ Triennal World Conference Pedagogy of Diversity: creating a culture of peace, 2005. Disponível em: http://www.uv.es/ soespe/Bartolome.htm. Acesso em 20 fev. 2020.

BANKS, James. Educating Citizens in a Multicultural Society. New York: Teachers College, Columbia University, 1997.

BENEDICTO, Jorge; MORÁN, María Luz. La construcción de una ciudadanía activa entre los jóvenes. Madrid: Injuve y Ministerio de Trabajo e Asuntos Sociales, 2002.

BÏRZEA, César. Education for Democratic Citizenship: lifelong learning perspective. Estrasburgo: Conselho da Europa. Council for Cultural Co-operation DGIV/EDU/CIT (21), 2000.

CANALS, Roser; PAGÈS, Joan. Competencia social i ciutadana. In: ZABALA, A. (Ed.), Qué, quan i com ensenyat les competències bàsiques a secundaria. Proposta de desplegament curricular. Barcelona: Gráo (traducción al castellano), 2011, p. 103-112.

CARDOSO, Jorge; TEOTÓNIO PEREIRA, Luísa; NEVES, Maria José (Coords.). Referencial de Educação para o Desenvolvimento - Educação Pré-Escolar, Ensino Básico e Ensino Secundário. Lisboa: Instituto Camões, CIDAC, FGS, 2016.

CLAUDINO, SÉRGIO. O Ensino de Geografia em Portugal: uma perspectiva. Inforgeo, n. 15, p. 183204, 2000.

CLAUDINO, Sérgio; HORTAS, Maria João. La enseñanza de la Geografia y de las Ciencias Sociales y la formación del professorado para la cuidadanía en Portugal. Perspectiva histórica, modelos, representaciones y desafios. In: BORGHI, B.; GARCÍA-PÉREZ, F.; MORENO-FERNÁNDEZ, O. (Coords.), Novi Cives Cittadini dall'Infanzia in Poi. Bologna: Pàtron Editore, 2015, p. 173-190.

COMISSÃO EUROPEIA. Eurydice Síntese - A Educação para a Cidadania nas Escolas da Europa 2017, 2018. Disponível em: https://op.europa.eu/en/publication-detail/-/publication/eof2801c184C-11e8-ac73-01aa75ed71a1/language-pt. Acesso em 12 jan. 2020. 
DIREÇÃO GERAL DE EDUCAÇÃO. Aprendizagens essenciais. Ensino básico, 2018. Acesso em: https://www.dge.mec.pt/aprendizagens-essenciais-ensino-basico. Acesso em 24 fev. 2020.

IPAD. Uma Visão Estratégica para a Cooperação Portuguesa. Lisboa: Instituto Português de Apoio ao Desenvolvimento, 2006.

IPAD. Estratégia Nacional de Educação para o Desenvolvimento (2010-2015). Lisboa: Instituto Português de Apoio ao Desenvolvimento, 2010.

MAIZTEGUI, Concha; EIZAGUIRRE, Marlen. Ciudadanía y Educación: de la teoria a la práctica. Bilbao: Universidad de Deusto, 2008.

MARTINS, Guilherme de Oliveira; GOMES, Carlos; BROCARDO, Joana; PEDROSO, José; CARRILLO, José; SILVA, Luísa; ENCARNAÇÃO, Maria Manuela; HORTA, Maria João; CALÇADA, Maria Teresa; NERY, Rui; RODRIGUES, Sónia. Perfil dos alunos à saída da escolaridade obrigatória. Lisboa: Ministério da Educação, Direção Geral de Educação, 2018.

MINISTÉRIO DA EDUCAÇÃO (Ed.). Educação, Integração, Cidadania. Documento Orientador das Políticas para o Ensino Básico. Lisboa: Ministério da Educação, 1998.

NOGUEIRA, Fernanda. O Espaço e o Tempo da cidadania na educação, Revista Portuguesa de Pedagogia, n. 49-1, p. 7-32, 2015.

PAGÈS, Joan. ¿Hacia dónde va la enseñanza de la historia y de las ciencias sociales?. Apuntes para la comprensión de un debate. Éndoxa, n. 1(14), p. 261-288, 2001.

PINTASSILGO, Joaquim (1998). República e formação de cidadãos. A educação cívica nas escolas primárias da $1^{a}$ República portuguesa. Lisboa: Edições Colibri, 1998.

ROSS, Alistair. Children's political learning: concept-based approaches versus issued-based approaches. In: ROLAND-LEVY, C.; ROSS, A. (Org.), Political Learning and Citizenship in Europe. Londres: Trentham Books, p. 15-32, 2003.

SÁ COSTA, Alexandra; CARAMELO, João (Coords.). Avaliação Externa. Estratégia Nacional de Educação para o Desenvolvimento 2010-2015. Relatório Final. Porto: Universidade do Porto, 2017.

SCHULZ, Wolfram, AINLEY, John, FRAILLON, Julian, LOSITO, Bruno, AGRUSTI, Gabriella; FRIEDMAN, Tim. Becoming Citizens in a Changing World: IEA International Civic and Citizenship Education Study 2016 International Report. Amsterdam: IEA, 2017.

VERA-VÁSQUEZ, Miguel. La formación del pensamento crítico: conceptualización y evaluación para alunos de $5^{\circ}$ de secundaria [Tese de licenciatura não publicada]. Faculdade de Ciências da Educação da Universidade de Piura, 2018.

Recebido em: 31/03/2020

Alterações recebidas e: 26/04/2020

Aceito em: 26/04/2020

Publicado em: 26/04/2020 